LESSONS LEARNED AT THE INTERFACE OF MEDICINE and Psychiatry

The Psychiatric Consultation Service at Massachusetts General Hospital (MGH) sees medical and surgical inpatients with comorbid psychiatric symptoms and conditions. Such consultations require the integration of medical and psychiatric knowledge. During their twice-weekly rounds, Dr Stern and other members of the Consultation Service discuss the diagnosis and management of conditions confronted. These discussions have given rise to rounds reports that will prove useful for clinicians practicing at the interface of medicine and psychiatry.

Dr Quinn is an assistant professor at the Department of Psychiatry, University of New Mexico (UNM) and an attending physician on the psychiatric consultation service at UNM Hospital. Dr Stern is chief of the Psychiatric Consultation Service at MGH in Boston and a professor of psychiatry at Harvard Medical School.

The authors report no financial or other relationship relevant to the subject of this article.

Corresponding author:

Davin K. Quinn, MD

University of New Mexico

2600 Marble Ave NE

Albuquerque, NM 87505

(dkquinn@hotmail.com)

doi:10.4088/PCC.09r00853

(C) Copyright 2009

Physicians Postgraduate Press, Inc.

\section{Linezolid and Serotonin Syndrome}

\author{
Davin K. Quinn, MD, and Theodore A. Stern, MD
}

$\mathbf{H}$ ave you ever wondered if problems might arise when a patient taking an antidepressant needs linezolid for treatment of methicillinresistant Staphylococcus aureus (MRSA) or vancomycin-resistant Enterococcus (VRE) infection? Have you wondered what complications might follow such coadministration? Have you been apprehensive when deciding whether a washout interval is needed before or after use of linezolid and a serotonergic antidepressant? If so, then the following questions and answers should stimulate discussion and provide much needed information.

\section{DEFINITION OF THE PROBLEM}

Linezolid is an oxazolidinone antibiotic that is widely used in general hospitals. Originally discovered as a psychotropic agent with antidepressant effects through mild reversible nonselective inhibition of monoamine oxidase (MAO), it was also found to have antibiotic efficacy against drugresistant gram-positive cocci (eg, MRSA and VRE). ${ }^{1}$ In patients taking linezolid along with serotonin agonists, there is a small but documented risk for serotonin syndrome (Table 1 provides a list of serotonin agonists). On the basis of this risk, clinicians often have to decide whether to discontinue either linezolid or a selective serotonin reuptake inhibitor (SSRI) in situations in which both medications are present. Some authors suggest applying the same stringent guidelines to linezolid regarding MAOinhibiting antidepressants and their interactions with serotonergic agents, although it is unclear whether the risk of serotonin syndrome is high enough to warrant this.

\section{WHAT IS THE SEROTONIN SYNDROME, AND HOW IS IT DIAGNOSED?}

Serotonin syndrome, also known as serotonin toxicity, is caused by excessive levels of circulating serotonin in the central nervous system (CNS) and the periphery. ${ }^{2}$ The syndrome is characterized by mental status changes, autonomic hyperactivity, and neuromuscular abnormalities that may range in severity from almost imperceptible to lethal. ${ }^{3}$ The majority of cases develop within 6 hours of initiation of medication or a change in medication that increases serotonin levels. Table 2 lists the spectrum of signs, symptoms, and states found in cases of serotonin toxicity. ${ }^{3}$

Mild serotonin toxicity may be manifested by tachycardia, shivering, diaphoresis, mydriasis, tremor, myoclonus, restlessness or an inability to sit still, or hyperreflexia. When the syndrome is moderately severe, signs and symptoms include the above-mentioned features, as well as hypertension, hyperthermia, hyperactive bowel signs, inducible clonus of the extremities, ocular clonus, agitation, hypervigilance, and pressured speech. ${ }^{3}$ Severe cases of serotonin syndrome also involve autonomic instability (leading to shock), delirium, and muscular rigidity. Other consequences 


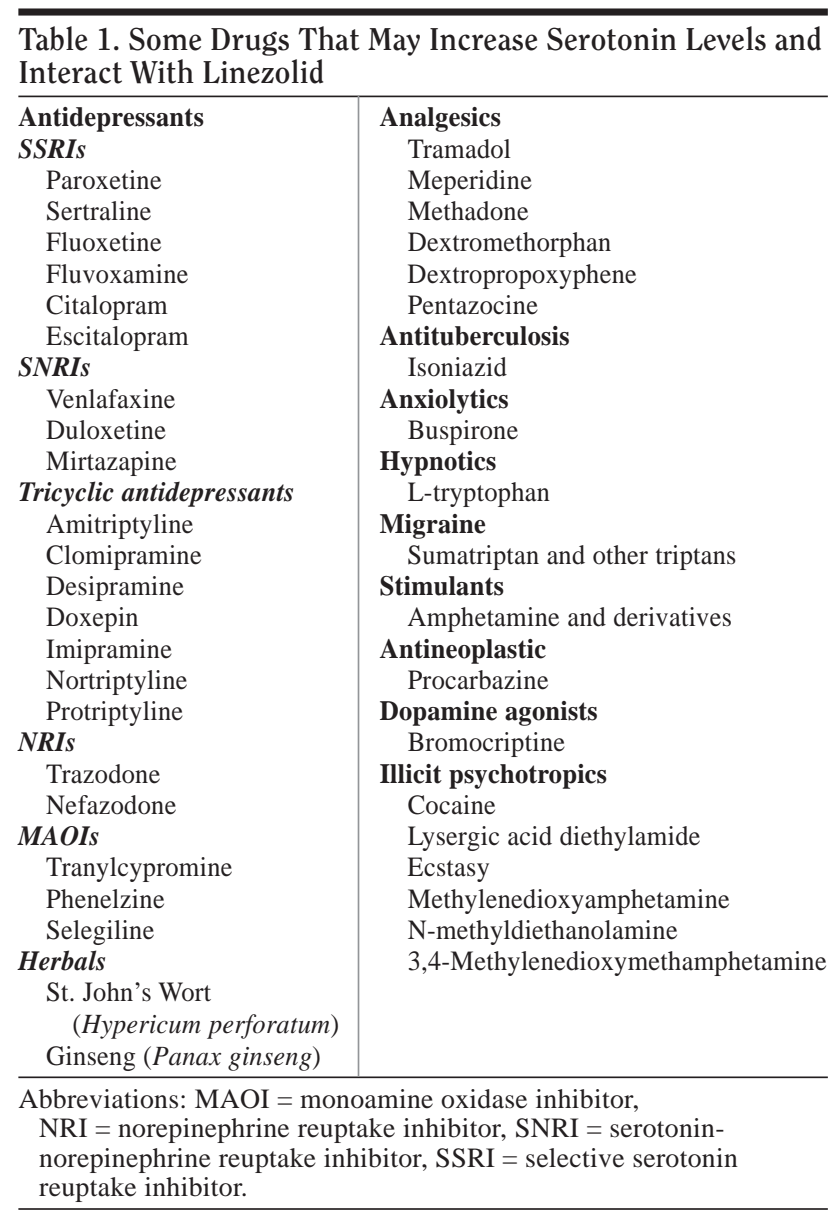

of severe serotonin syndrome include metabolic acidosis, rhabdomyolysis, creatinine and aminotransferase elevations, seizures, renal failure, and disseminated intravascular coagulation. ${ }^{3}$ Unfortunately, there are no laboratory tests that confirm a diagnosis of serotonin syndrome.

While no tests confirm the diagnosis of serotonin syndrome, 2 criteria sets have been developed to identify the presence of serotonin toxicity (Table 3). Sternbach's criteria require at least 3 of the following to be present in the absence of neuroleptic use and other explanatory etiologies: mental status changes, agitation, myoclonus, hyperreflexia, diaphoresis, shivering, tremor, diarrhea, incoordination, and fever. ${ }^{2}$ Boyer's criteria require any of the following, with a serotonergic agent being administered in the preceding 5 weeks: tremor and hyperreflexia, spontaneous clonus, muscle rigidity and temperature $>38^{\circ} \mathrm{C}$ and either ocular clonus or inducible clonus, ocular clonus and either diaphoresis or agitation, and inducible clonus and either diaphoresis or agitation. ${ }^{3}$ It has been noted that Boyer's criteria are more specific for serotonin toxicity than are Sternbach's criteria. ${ }^{4}$
Table 2. Spectrum of Signs, Symptoms, and States in Serotonin Syndrome ${ }^{\mathrm{a}}$

\begin{tabular}{|c|c|c|}
\hline Mild & $\begin{array}{c}\text { Moderate (mild } \\
\text { symptoms and ....) }\end{array}$ & $\begin{array}{l}\text { Severe (moderate } \\
\text { symptoms and ...) }\end{array}$ \\
\hline Tachycardia & Hypertension & Autonomic instability \\
\hline Shivering & Hyperthermia & Agitated delirium \\
\hline Diaphoresis & $\begin{array}{l}\text { Hyperactive bowel } \\
\text { sounds }\end{array}$ & Muscular rigidity \\
\hline Mydriasis & Inducible clonus & Metabolic acidosis \\
\hline Intermittent tremor & Ocular clonus & Rhabdomyolysis \\
\hline Myoclonus & Agitation & Kidney failure \\
\hline Akathisia & Hypervigilance & Seizures \\
\hline Hyperreflexia & Pressured speech & $\begin{array}{l}\text { Disseminated intravascular } \\
\text { coagulation }\end{array}$ \\
\hline
\end{tabular}

Table 3. Sternbach's and Boyer's Criteria for Serotonin Syndrome

\begin{tabular}{lc}
\hline Sternbach's Criteria $^{2}$ & Boyer's Criteria $^{3}$ \\
\hline At least 3 of the following required: & Any 1 of the following required: \\
Mental status changes & Tremor and hyperreflexia \\
Agitation & Spontaneous clonus \\
Myoclonus & Muscle rigidity, temperature \\
Hyperreflexia & $>38^{\circ} \mathrm{C}$, and ocular \\
Diaphoresis & or inducible clonus \\
Shivering & Ocular clonus and diaphoresis \\
Tremor & or agitation \\
Diarrhea & Inducible clonus and \\
Incoordination & diaphoresis or agitation \\
Fever & \\
\hline
\end{tabular}

\section{WHAT IS THE MECHANISM OF AND TREATMENT FOR SEROTONIN SYNDROME?}

While the mechanism of serotonin toxicity is not fully known, it is believed to involve an excess of agonism of 5-HT receptors in the CNS and peripheral tissues through elevated synaptic concentrations of serotonin. ${ }^{3}$ Drugs in the MAO-inhibitor class-for example, linezolid—cause increases in synaptic concentrations of biogenic amines (eg, dopamine, norepinephrine, and serotonin). When these agents are combined with proserotonergic agents, synaptic concentrations of serotonin rise to toxic levels and precipitate the syndrome.

The treatment of serotonin toxicity includes removal of the offending agent(s), control of agitation, administration of 5-HT2a antagonists, and autonomic stabilization. ${ }^{5}$ Cases usually resolve within 24 hours of initiation of therapy but may take longer depending on the half-life of the offending agent(s).

\section{WHAT IS THE PREVALENCE OF LINEZOLID-INDUCED SEROTONIN TOXICITY?}

No randomized controlled trials or prospective cohort studies have examined the rate of serotonin toxicity in patients receiving linezolid and serotonergic agents. In US 


\begin{tabular}{|c|c|c|c|c|c|c|}
\hline Study & $\begin{array}{c}\text { Age of } \\
\text { Patient }(y)\end{array}$ & Serotonergic Agent & Diagnosis & $\begin{array}{l}\text { Washout } \\
\text { Period }(\mathrm{d})\end{array}$ & $\begin{array}{c}\text { Time to } \\
\text { Onset }\end{array}$ & $\begin{array}{l}\text { Time to } \\
\text { Resolution }\end{array}$ \\
\hline Wigen and Goetz, $2002^{8}$ & 56 & Paroxetine & Surgical abscess, cirrhosis & 3 & $<24 \mathrm{~h}$ & $48 \mathrm{~h}$ \\
\hline Thomas et al, $2004^{9}$ & 4 & $\begin{array}{l}\text { Fluoxetine } \\
\text { Fentanyl }\end{array}$ & Burns & 0 & $1 \mathrm{~h}$ & $48 \mathrm{~h}$ \\
\hline DeBellis et al, $2005^{10}$ & 56 & Citalopram, mirtazapine & Urinary tract infection & 0 & $4 \mathrm{~d}$ & $48 \mathrm{~h}$ \\
\hline Jones et al, $2004^{11}$ & 85 & Venlafaxine & Infected prosthesis & 0 & $20 \mathrm{~d}$ & $48 \mathrm{~h}$ \\
\hline Bergeron et al, $2005^{12}$ & 38 & Venlafaxine & Cystic fibrosis & 0 & $4 \mathrm{~d}$ & $24 \mathrm{~h}$ \\
\hline Bergeron et al, $2005^{12}$ & 37 & Citalopram & Cellulitis, multiple myeloma & 0 & $3 \mathrm{~d}$ & $5 \mathrm{~d}$ \\
\hline Bernard et al, $2003^{13}$ & 81 & Citalopram & Osteomyelitis & 0 & $3 \mathrm{wk}$ & NA \\
\hline Tahir, $2004^{14}$ & 85 & Citalopram & Staph bacteremia & 0 & $<24 \mathrm{~h}$ & $3 \mathrm{~d}$ \\
\hline Hachem et al, $2003^{15}$ & 56 & Citalopram & $\begin{array}{l}\text { Acute myelogenous leukemia, } \\
\text { congestive heart failure }\end{array}$ & 0 & $2 \mathrm{~d}$ & $9 \mathrm{~d}$ \\
\hline Hachem et al, $2003^{15}$ & 36 & Sertraline & Chronic lymphocytic leukemia & 0 & $5 \mathrm{~d}$ & $24 \mathrm{~h}$ \\
\hline Lavery et al, $2001^{16}$ & 45 & Sertraline & Sacral decubitus ulcer & 0 & $10 \mathrm{~d}$ & $48 \mathrm{~h}$ \\
\hline $\begin{array}{l}\text { Morales and } \\
\quad \text { Vermette, } 2005^{17}\end{array}$ & 39 & Fluoxetine & Delirium, aspiration & 18 & $<24 \mathrm{~h}$ & $48 \mathrm{~h}$ \\
\hline Taylor et al, $2006^{18}$ & 30 & Sertraline, fentanyl & Pancreatic pseudocyst & 0 & $<24 \mathrm{~h}$ & $24 \mathrm{~h}$ \\
\hline Taylor et al, $2006^{18}$ & 81 & $\begin{array}{l}\text { Venlafaxine, citalopram, } \\
\text { fentanyl }\end{array}$ & Urinary tract infection & 0 & $<24 \mathrm{~h}$ & $48 \mathrm{~h}$ \\
\hline Clark et al, $2006^{19}$ & 47 & Sertraline & Necrotic wound & 0 & $5 \mathrm{~d} / 8 \mathrm{~d}$ & $4 \mathrm{~d} / 4 \mathrm{~d}$ \\
\hline $\begin{array}{l}\text { Steinberg and } \\
\quad \text { Morin, } 2007^{20}\end{array}$ & 23 & Fluoxetine & Acute myelogenous leukemia & 0 & $9 \mathrm{~h}$ & $48 \mathrm{~h}$ \\
\hline Strouse et al, $2006^{21}$ & 55 & Duloxetine, fentanyl & Metastatic sarcoma & 0 & $3 \mathrm{~h}$ & $36 \mathrm{~h}$ \\
\hline
\end{tabular}

Food and Drug Administration (FDA) Phase III trials of linezolid, among 52 patients concurrently taking linezolid and SSRIs, no cases of serotonin syndrome were reported. ${ }^{6}$ Lawrence and colleagues $^{7}$ examined 2,222 documented cases of serotonergic poisoning reported to the FDA's Adverse Event Reporting System and found 29 cases of linezolid-associated serotonin toxicity; 13 of these required hospitalization. ${ }^{7}$ The most frequently occurring concurrent drugs in these cases were SSRIs. ${ }^{7}$

Since linezolid was approved by the FDA for use, there have been 17 published case reports documenting the occurrence of symptoms of serotonin toxicity in patients receiving linezolid and SSRIs. Taylor and colleagues, ${ }^{4}$ in a retrospective chart review of cases at the Mayo Clinic (Rochester, Minnesota), found an incidence of serotonin toxicity of $3 \%$ in patients taking SSRIs and linezolid. Table 4 lists the case reports found in the literature. ${ }^{8-21}$

Time to onset of symptoms ranged from $<24$ hours to 3 weeks, while time to resolution of symptoms once 1 or both of the drugs were discontinued ranged from 1 to 5 days. All but 2 of the case reports involve coadministration of a proserotonergic agent and linezolid, in which linezolid is added to a regimen already containing an SSRI. The 2 cases of nonoverlapping administration had washout periods of 3 days and 18 days. ${ }^{8,17}$

\section{WHEN MAY SSRIS AND LINEZOLID BE USED IN RELATION TO EACH OTHER?}

The clinical indications for use of linezolid and SSRIs concurrently or within close temporal relation to one an- other are prevalent, as resistant nosocomial infections and depressive disorder associated with medical illnesses are both common in US hospitals. Serotonin toxicity resulting from an adverse interaction between linezolid and SSRIs is a rare but potentially fatal iatrogenic complication, which is treated supportively and by removing the offending agent(s) from the drug regimen. The available case reports represent valuable but extremely limited information about the phenomenon; more empirical evidence concerning the true prevalence of and predisposing factors for serotonin syndrome will guide future recommendations for drug therapy.

Current recommendations for use of linezolid and SSRIs are based on risk-management heuristics, not clinical necessity and judgment. Guidelines promulgated by Micromedex (Micromedex Healthcare Series [Internet database], Thomson Reuters [Healthcare] Inc, Greenwood Village, Colorado) correspond to guidelines for use of MAO-inhibiting antidepressants (which have a much higher rate of serotonin toxicity when combined with SSRIs) and recommend separating administration of linezolid from SSRIs by 2 weeks (in the case of fluoxetine, the recommendation is 5 weeks, owing to its extremely long half-life). However, infection with a resistant organism is a serious illness, requiring prompt initiation of antibiotic therapy. Given its status as a weak MAO inhibitor with powerful antibiotic efficacy, for which a special tyramine-depleted diet is not needed, linezolid's use with SSRIs should be dictated by informed clinical judgment. We propose that if a patient is taking an SSRI and requires linezolid for a new infection, 
the initiation of linezolid should not be delayed to washout the SSRI.

The SSRI-treated patient who is newly started on linezolid should be observed for emerging signs and symptoms of serotonin toxicity for at least 3 weeks. While there are no case reports of toxicity occurring after periods of concurrent use longer than 3 weeks, instances of linezolid being used beyond 3 weeks are not common. A patient who continues taking SSRIs and linezolid beyond that time period should be closely observed for emergence of symptoms of toxicity. Every patient should also have a thorough vetting of their medication regimen for other lesser-known proserotonergic agents (eg, meperidine and tramadol).

The question of whether to stop the SSRI when linezolid is administered, or leave it in the patient's medication regimen, must be decided according to cost-benefit analysis of the clinical situation. Is the risk of serotonin syndrome greater than the risk of recurrent mood or anxiety disorder? At one extreme, if a patient is intubated, sedated, paralyzed, and critically ill, continuing the antidepressant would be a lesser clinical priority than avoiding a rare but consequential episode of drug toxicity that could exacerbate the critical illness or hasten the failure of multiple organ systems.

At the other extreme, in a chronically mentally ill outpatient with osteomyelitis who needs oral linezolid for an indefinite period of time, the risk and consequence of an exacerbation of a brittle mental illness may be far greater than the rare risk of serotonin syndrome. This patient may be maintained on linezolid and a serotonergic agent concurrently, with frequent clinical follow-up to monitor for serotonin toxicity, especially during the first month of treatment. Because the incidence of serotonin toxicity is so low, there are no data regarding specific dosages of SSRIs that may increase the risk of serotonin toxicity; clinicians should use medication dosages as part of their cost-benefit analysis.

When may an SSRI be started if a patient is receiving linezolid and is found to have a depressive disorder? Again, a cost-benefit analysis of the situation determines the therapy. Delaying the initiation of the SSRI until 2 weeks after the discontinuation of linezolid is a conservative maneuver in accordance with the guidelines for MAOinhibiting antidepressants and may be done in patients for whom the serious consequences of a rare drug interaction far outweigh the consequences of untreated mental illness, such as in critically ill patients. The half-life of linezolid is approximately 5 hours. Initiating an SSRI less than 2 weeks after treatment with linezolid should be considered for patients whose clinical status would likely suffer without timely administration of the treatment, as in severe mood disorders with suicidal or homicidal ideation, psychosis, or debilitating neurovegetative symptoms (eg, inanition).

\section{CONCLUSION}

In sum, based on the overall low incidence of serotonin syndrome when linezolid and SSRIs are simultaneously administered, the effectiveness of treatment for serotonin syndrome, and the paucity of prospective data on the phenomenon, we assert that decisions regarding cessation or initiation of SSRIs with linezolid may be based on riskbenefit analyses, rather than risk-management heuristics.

\section{REFERENCES}

1. Moellering RC. Linezolid: the first oxazolidinone antimicrobial. Ann Intern Med. 2003;138(2):135-142.

2. Sternbach H. The serotonin syndrome. Am J Psychiatry. 1991;148(6): 705-713.

3. Boyer EW, Shannon M. The serotonin syndrome. N Engl J Med. 2005; 352(11):1112-1120.

4. Taylor JJ, Wilson JW, Estes LL. Linezolid and serotonergic drug interactions: a retrospective survey. Clin Infect Dis. 2006;43(2): 180-187.

5. Gillman PK. The serotonin system and its treatment. J Psychopharmacol.1999;13(1):100-109.

6. Rubinstein E, Isturiz R, Standiford HC, et al. Worldwide assessment of linezolid's clinical safety and tolerability: comparator-controlled phase III studies. Antimicrob Agents Chemother. 2003;47(6):1824-1831.

7. Lawrence KR, Adra M, Gillman PK. Serotonin toxicity associated with the use of linezolid: a review of postmarketing data. Clin Infect Dis. 2006;42(11):1578-1583.

8. Wigen CL, Goetz MB. Serotonin syndrome and linezolid. Clin Infect Dis. 2002;34(12):1651-1652.

9. Thomas CR, Rosenberg M, Blythe V, et al. Serotonin syndrome and linezolid. J Am Acad Child Adolesc Psychiatry. 2004;43(7):790.

10. DeBellis RJ, Schaefer OP, Liquori M, et al. Linezolid-associated serotonin syndrome after concomitant treatment with citalopram and mirtazepine in a critically ill bone marrow transplant recipient. J Intensive Care Med. 2005;20(6):351-353.

11. Jones SL, Athan E, O'Brien D. Serotonin syndrome due to co-administration of linezolid and venlafaxine. J Antimicrob Chemother. 2004;54(1):289-290.

12. Bergeron L, Boulé M, Perreault S. Serotonin toxicity associated with concomitant use of linezolid. Ann Pharmacother. 2005;39(5):956-961.

13. Bernard L, Stern R, Lew D, et al. Serotonin syndrome after concomitant treatment with linezolid and citalopram. Clin Infect Dis. 2003;37(9): 1274-1275.

14. Tahir N. Serotonin syndrome as a consequence of drug-resistant infections: an interaction between linezolid and citalopram. J Am Med Dir Assoc. 2004;5(2):111-113.

15. Hachem RY, Hicks K, Huen A, et al. Myelosuppression and serotonin syndrome associated with concurrent use of linezolid and selective serotonin reuptake inhibitors in bone marrow transplant recipients. Clin Infect Dis. 2003;37(1):e8-e11.

16. Lavery S, Ravi H, McDaniel WW, et al. Linezolid and serotonin syndrome. Psychosomatics. 2001;42(5):432-434.

17. Morales N, Vermette H. Serotonin syndrome associated with linezolid treatment after discontinuation of fluoxetine. Psychosomatics. 2005; 46(3):274-275.

18. Taylor JJ, Estes LL, Wilson JW. Linezolid and serotonergic drug interactions. Clin Infect Dis. 2006;43(2):180-187.

19. Clark DB, Andrus MR, Byrd DC. Drug interactions between linezolid and selective serotonin reuptake inhibitors: case report involving sertraline and review of the literature. Pharmacotherapy. 2006;26(2):269-276.

20. Steinberg M, Morin AK. Mild serotonin syndrome associated with concurrent linezolid and fluoxetine. Am J Health Syst Pharm. 2007;64(1): 59-62.

21. Strouse TB, Kerrihard TN, Forscher CA, et al. Serotonin syndrome precipitated by linezolid in a medically ill patient on duloxetine. J Clin Psychopharmacol. 2006;26(6):681-683. 